\title{
ANALISA RESISTIVITAS KAWAT PENGHANTAR DITINJAU DARI METODE JEMBATAN WHEATSTONE DAN METODE HUKUM OHM PADA MODUL PRAKTIKUM FISIKA
}

(Studi Kasus pada Lab. Fisika Fakultas Teknik Universitas Pembangunan Nasional ”Veteran” Jakarta)

Tatik Juwariyah ${ }^{1)}$, Yuhani Djaya ${ }^{2)}$

Fakultas Teknik, Universitas Pembangunan Nasional "Veteran" Jakarta ${ }^{12}$

email: tatik_j@yahoo.com

\begin{abstract}
The analysis of the resistivity of a wire based on the Wheatstone bridge method and the Ohm law method in physics experiment module has been done. The analysis of the resistivity of a wire was done in a physics laboratory at UPNVJ engineering faculty. This topic was studied because there has been no experiment in the themed of electricity in the physics experiment module at the faculty of engineering UPNVJ. The most popular method applied to obtain wire resistivity value is the Ohm law method. In order to enlarge the understanding of the electricity concept, this research needed other method that can be used to find out the wire resistivity namely the Wheatstone Bridge method. This research aimed to obtain the resistivity value of Nichrome wire from two different methods. The methods were the Ohm law method and the Wheatstone bridge method. In Ohm law method, the wire length was subsequent varied. Then, the electric voltage value and an electric current were recorded. While in the Wheatstone bridge method, it was used circuit bridge. The value of the variable resistor was varied and the segment length metal plate was measured. The data were processed in order to obtain the Nichrome wire resistivity values by linear regression method. From Ohm law method and the Wheatstone bridge method were respectively obtained the value of Nichrome wire was $\rho \pm \Delta \rho=(2,875 \pm 0,005) \times 10^{-6} \Omega \mathrm{m}$ and $\rho \pm \Delta \rho=(5,00 \pm 0,25) \times 10^{-6} \Omega \mathrm{m}$. The results of the two methods are match with the value of the standard of the Nichrome wire is $\rho=1,0 \times 10^{-6} \Omega \mathrm{m}$. By using the two methods, it was expected that the students' understanding of the electricity concept was increasingly widespread.
\end{abstract}

Keywords: resistivity, Ohm law, Wheatstone Bridge, linear regression.

\section{PENDAHULUAN}

Topik percobaan Resistivitas Kawat merupakan salah satu topik utama di percobaan bertema kelistrikan yang dipraktekkan di mata kuliah Praktikum Fisika(Dasar). Metode paling populer yang diterapkan untuk mendapatkan nilai resistivitas kawat adalah metode hukum Ohm. Metode hukum Ohm diterapkan karena pada prakteknya metode ini cukup sederhana, sehingga mudah dipahami oleh mahasiswa. Kesederhanaan metode hukum Ohm terlihat dari bentuk rangkaian listrik yang dipakai. Hanya dengan memvariasi panjang kawat dan mencatat nilai tegangan listrik dan arus listrik maka nilai resistivitas kawat dapat diperoleh. Guna menambah wawasan pemahaman mengenai konsep kelistrikan diperlukan metode lain yang dapat digunakan untuk mencari resistivitas kawat. Penelitian ini bertujuan mendapatkan nilai resistivitas kawat Nikrom dari dua metode yang berbeda yaitu metode hukum Ohm dan metode Jembatan Wheatstone.

\section{TINJAUAN PUSTAKA}

Praktikum Fisika Dasar di tingkat universitas pada umumnya terdiri dari empat tema utama yaitu mekanika, optika, kalor dan listrik-magnet (Squires, G.L., 1968). Topik percobaan listrik-magnet diantaranya adalah multimeter, hukum ohm, tahanan dalam, transformartor, mengenal alat ukur listrik dan osiloskop sinar katoda (Tim Penyusun, 2010).

\section{2.a Analisis Resistivitas Kawat dengan metode hukum Ohm}

Hambatan(resistance) suatu penghantar dapat ditentukan dengan mengukur perbedaan potensial antara ujung-ujung penghantar dan mengukur kuat arus yang melalui penghantar tersebut. Hukum Ohm menyatakan bahwa besarnya nilai beda potensial antara ujung-ujung penghantar sebanding dengan kuat arus yang melaluinya.

$$
R=V / I
$$


Jika di antara ujung-ujung penghantar sepanjang $l$ dipasang beda tegangan $\mathrm{V}$, maka besarnya medan listrik $E$ dapat dituliskan sebagai berikut :

$$
E=V / l
$$

Rapat arus listrik $j$ dinyatakan sebagai perbandingan kuat arus I tiap luas penampang penghantar A (Giancolli, 2001) :

$$
j=I / A
$$

Tahanan dalam atau resitivitas (resistivity) merupakan karakteristik suatu bahan penghantar didefinisikan (Tipler, A.P, 2001):

$$
\rho=E / j
$$

Substitusi persamaan (2) dan (3) ke dalam persamaan (4) diperoleh :

$$
\rho=\frac{V / l}{I / A}
$$

Dengan menggunakan definisi $\mathrm{R}=\mathrm{V} / \mathrm{I}$, maka persamaan (5) dapat ditulis sebagai :

$$
\rho=R A / l
$$

Dari persamaan diatas dapat ditentukan nilai resistivitas bahan penghantar dengan cara memvariasikan panjang penghantar $l$ dan mengukur nilai $\mathrm{R}=\mathrm{V} / \mathrm{I}$ pada penghantar yang memiliki luas penampang konstan (Tim Penyusun, 2013).

2.b Analisis resistivitas dengan metode Jembatan

\section{Wheatstone}

Rangkaian listrik Jembatan Wheatstone adalah salah satu rangkaian listrik jembatan(electrical bridge). Rangkaian Listrik Jembatan Wheatstone biasanya digunakan untuk mengukur tahanan $\mathrm{R}$ suatu bahan yang tidak diketahui nilainya (Sutrisno, 1986). Secara sederhana skema rangkaian Jembatan Wheatstone yang digunakan untuk mencari tahanan dilukiskan pada Gambar 1.

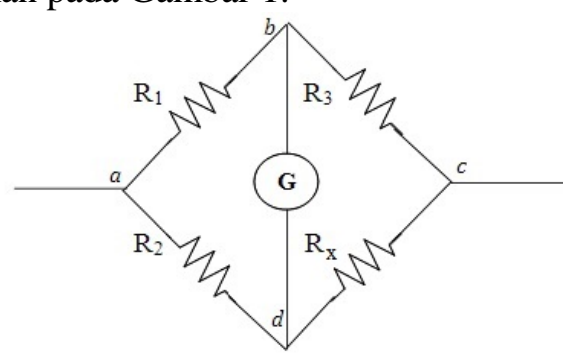

Gambar 1. Rangkaian jembatan Wheatstone

Prinsip jembatan Wheatstone memenuhi kaidah bahwa jika tidak ada arus listrik yang mengalir melewati Galvanometer, artinya $\mathrm{V}_{\mathrm{bd}}=0$, ini mengakibatkan $\mathrm{V}_{\mathrm{ab}}=\mathrm{V}_{\mathrm{ad}}$ dan $\mathrm{V}_{\mathrm{bc}}=\mathrm{V}_{\mathrm{dc}}$ serta $\mathrm{i}_{1}=1_{3}$ dan $i_{2}=i_{x}$ sehinggga $i_{G}=0$.

Jika $\mathrm{V}_{\mathrm{ab}}=\mathrm{V}_{\mathrm{ad}}$, maka hal ini berarti,

$$
I_{1} R_{1}=I_{2} R_{2}
$$

Dan jika $\mathrm{V}_{\mathrm{bc}}=\mathrm{V}_{\mathrm{dc}}$, maka artinya

$$
I_{3} R_{3}=I_{4} R_{x}
$$

Dengan membagi persamaan (7) terhadap persamaan (8) dan menganggap bahwa $i_{1}=1_{3}$; $\mathrm{i}_{2}=\mathrm{i}_{4}$ diperoleh kaitan :

Sehingga

$$
\frac{I_{1} R_{1}}{I_{3} R_{3}}=\frac{I_{2} R_{2}}{I_{4} R_{x}}
$$

$$
R_{x}=\frac{R_{2} R_{3}}{R_{1}}
$$

\section{METODE PENELITIAN}

Penelitian ini adalah penelitian kuantitatif sehingga memiliki tahap-tahap sebagai berikut :

1. Studi pustaka terkait pengukuran resistivitas kawat penghantar ditinjau dari metode hukum Ohm dan metode jembatan Wheatstone.

2. Persiapan peralatan dan bahan eksperimen.

3. Merangkai peralatan dan melakukan pengambilan data eksperimen.

Pada metode hukum Ohm dilakukan variasi panjang kawat dan diukur besarnya tegangan dan kuat arus yang mengalir pada setiap variasi panjang kawat.

Pada metode jembatan Wheatstone digunakan pendekatan sebagai berikut :

Dua resistor yaitu $\mathrm{R}_{1}$ dan $\mathrm{R}_{3}$ dapat diganti dengan sebuah plat logam, sehingga rangkaian Jembatan Wheatstone menjadi seperti tampak pada Gambar 2.

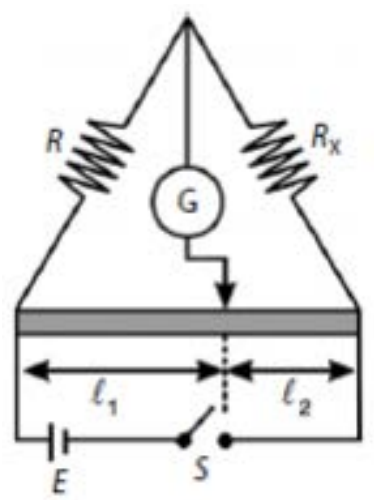

Gambar 2. Skema rangkaian peralatan metode jembatan Wheatstone

Pada batang/plat logam, dilakukan penggeseran kabel penghubung dari Galvanometer sedemikian sehingga Galvanometer tidak mendeteksi adanya arus yang mengalir pada Galvanometer, artinya

$$
R_{x}=\frac{R_{l 2}}{R_{l 1}} R
$$

Mengingat bahwa $\mathrm{R}=\rho . / / \mathrm{A}$ maka persamaan di atas menjadi : 


$$
R_{x}=\frac{\rho L_{2} / A}{\rho L_{1} / A} R
$$

Karena batang logam segmen 1 dan segmen 2 adalah batang logam yang sama, maka

$$
R_{x}=\frac{l_{2}}{l_{1}} R
$$

4. Pengolahan data dengan metode regresi linier. Dengan asumsi data-data hasil eksperimen membentuk garis lurus maka pada data-data metode hukum Ohm dapat dianalogikan sebagai berikut,

$$
\begin{gathered}
\frac{V}{I}=\frac{\rho}{A} L \\
\downarrow_{\mathrm{m}} \downarrow_{\mathrm{x}} \downarrow
\end{gathered}
$$

dimana $\mathrm{y}=\mathrm{V} / \mathrm{I}$ (hasil pembacaan $\mathrm{V}$ dan I)

$$
\begin{aligned}
& \mathrm{x}=l \text { (variasi panjang kawat); } \\
& \mathrm{m}=\rho / \text { A sehingga } \rho=\mathrm{m} . \mathrm{A}
\end{aligned}
$$

Sementara pada metode Jembatan Wheatstone data-data eksperimen dianalogikan sebagai berikut :

$$
\begin{array}{r}
\frac{l_{1}}{l_{2}}=\frac{A}{\rho_{x} L} R \\
\mathrm{y}=\downarrow_{\mathrm{m}} \downarrow_{\mathrm{x}} \downarrow
\end{array}
$$

dimana $y=l_{1} / l_{2}$ (hasil pengukuran segmen plat logam)

$$
\mathrm{x}=\text { variasi resistor variabel }
$$$$
\mathrm{m}=\mathrm{A} / \rho \mathrm{L} \text { sehingga } \rho=\mathrm{A} / \mathrm{mL}
$$

5. Pembahasan hasil data eksperimen.

6. Kesimpulan.

Adapun diagram alir penelitian ini dapat ditunjukkan pada Gambar 3.

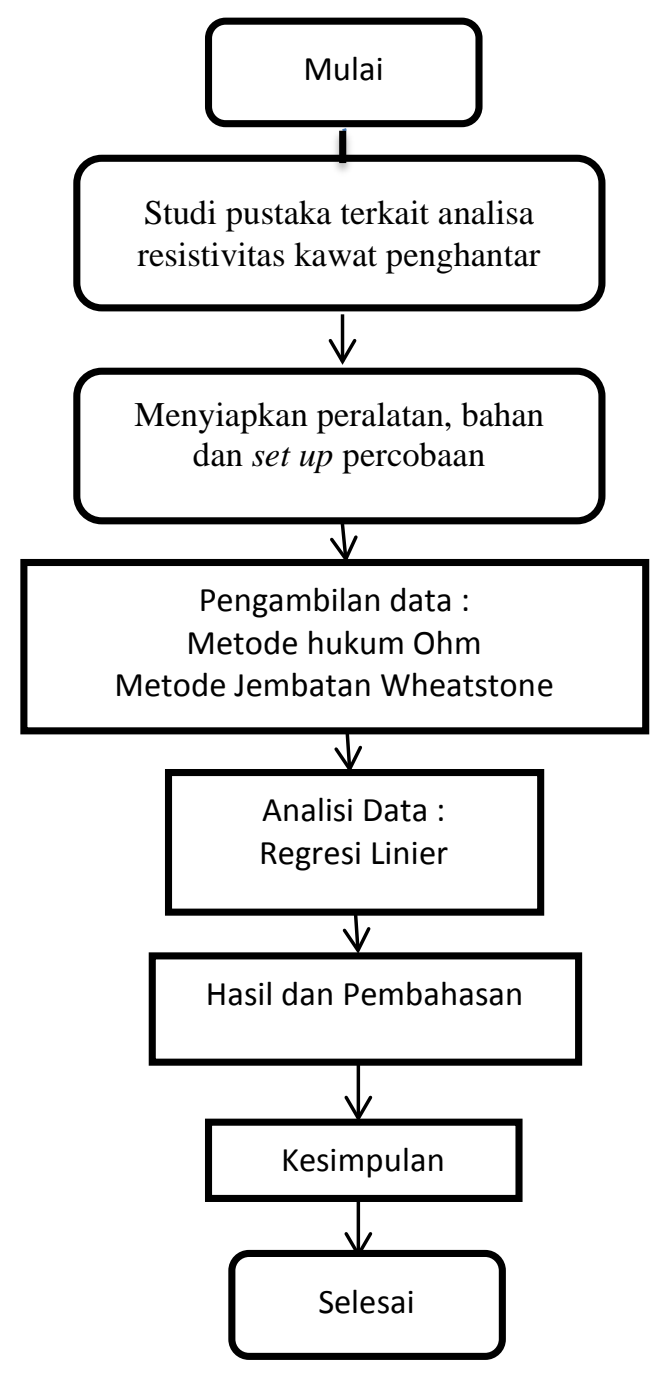

Gambar 3. Diagram alir tahapan penelitian

\section{HASIL DAN PEMBAHASAN}

Penelitian ini dilaksanakan di Laboratorium Fisika Fakultas Teknik UPN "Veteran” Jakarta pada suhu ruangan $=25{ }^{\circ} \mathrm{C}$ seperti ditunjukkan pada Gambar 4.

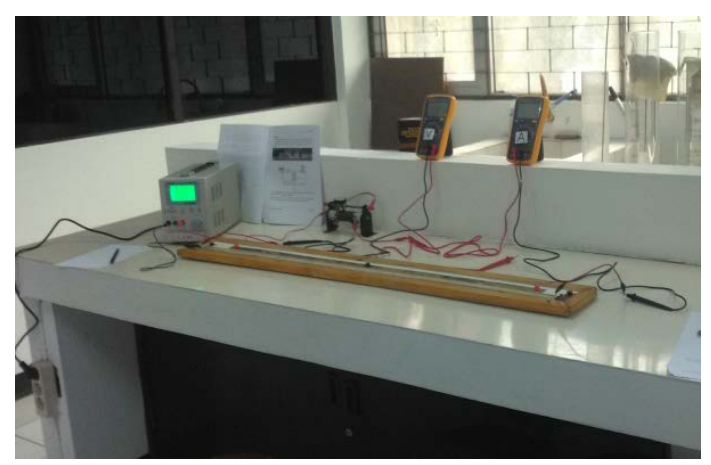

Gambar 4. Tempat penelitian

Peralatan dan bahan yang dipakai pada penelitian ini :

Metode Hukum Ohm :
1. Power Supply Digital : 1 unit
2. Kabel Jepit buaya : : 4 pasang 

3. Voltmeter Digital : 1 unit
4. Amperemeter Digital : 1 unit
5. Rheostat/resistor geser : 1 unit
6. Mistar 1 meter : 1 unit
7. Kawat Nikrom $\mathrm{d}=0,5 \mathrm{~mm} \quad: 1$ meter

Metode Jembatan Wheatstone

1. Papan Jembatan Wheatstone : 1 unit

2. Power Supply : 1 unit

3. Kabel Jumper : 7

4. Galvanometer : :1 unit

5. Mistar 1 meter $: 1$ unit

6. resistor tetap $: 10 \Omega-100 \Omega$

7. Kawat Nikrom Rx : 1 meter

Alat dan bahan dirangkai seperti pada Gambar 5 dan Gambar 6.

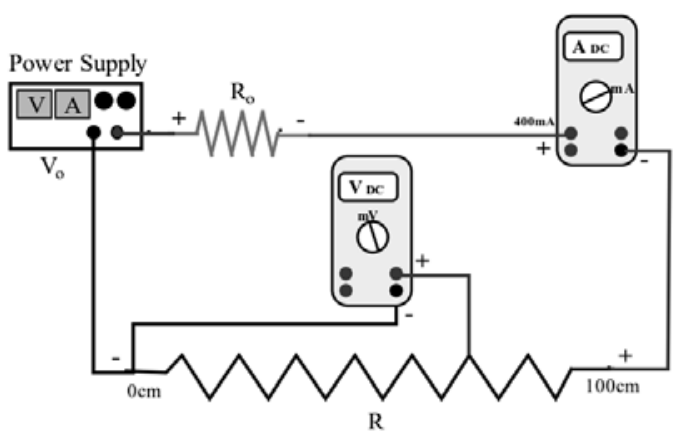

Gambar 5. Rangkaian hukum Ohm (www.csivc.csi.cuny.edu)

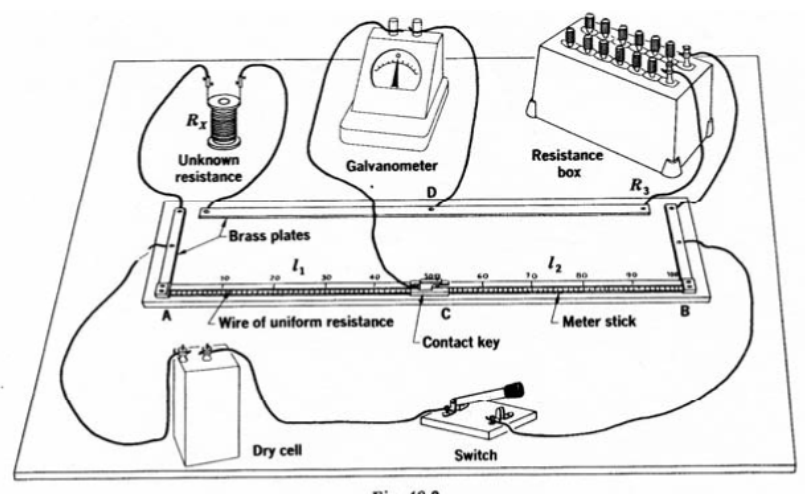

Gambar 6. Rangkaian Jembatan Wheatstone

Pada metode hukum Ohm diperoleh data sebagaimana tertulis pada Tabel 1 dan Tabel 2.

Tabel 1. Data I eksperimen resistivitas kawat dengan metode hukum Ohm

Daya Power Supply : V=1,0 V; I=0,01 A.

\begin{tabular}{|l|l|l|l|l|}
\hline NO & L (cm) & $\begin{array}{l}\text { V } \\
(\mathrm{mV})\end{array}$ & $\begin{array}{l}\text { I } \\
(\mathrm{mA})\end{array}$ & $\mathrm{R}(\mathrm{ohm})$ \\
\hline 1 & 10 & 19,3 & 13,3 & 1,45 \\
\hline 2 & 20 & 39,1 & 13,3 & 2,94 \\
\hline 3 & 30 & 58,7 & 13,3 & 4,41 \\
\hline
\end{tabular}

\begin{tabular}{|l|l|l|l|l|}
\hline 4 & 40 & 79 & 13,3 & 5,94 \\
\hline 5 & 50 & 98,6 & 13,3 & 7,41 \\
\hline 6 & 60 & 118,3 & 13,3 & 8,89 \\
\hline 7 & 70 & 137,9 & 13,3 & 10,37 \\
\hline 8 & 80 & 157,8 & 13,3 & 11,86 \\
\hline 9 & 90 & 177,4 & 13,3 & 13,33 \\
\hline 10 & 100 & 196,5 & 13,3 & 14,77 \\
\hline
\end{tabular}

Tabel 2. Data II eksperimen resistivitas kawat dengan metode hukum Ohm

Daya Power Supply : V=5,0 V; I=0,04 A.

\begin{tabular}{|r|r|r|r|r|}
\hline NO & $\begin{array}{c}\mathrm{L} \\
(\mathrm{cm})\end{array}$ & $\begin{array}{c}\mathrm{I} \\
(\mathrm{mA})\end{array}$ & $\begin{array}{c}\mathrm{V} \\
(\mathrm{mV})\end{array}$ & \multicolumn{1}{c|}{$\mathrm{R}(\mathrm{ohm})$} \\
\hline 1 & 10 & 37,83 & 60 & 1,586 \\
\hline 2 & 20 & 37,83 & 115 & 3,039 \\
\hline 3 & 30 & 37,83 & 171 & 4,520 \\
\hline 4 & 40 & 37,83 & 227 & 6,000 \\
\hline 5 & 50 & 37,83 & 282 & 7,454 \\
\hline 6 & 60 & 37,83 & 329 & 8,696 \\
\hline 7 & 70 & 37,83 & 394 & 10,415 \\
\hline 8 & 80 & 37,83 & 449 & 11,868 \\
\hline 9 & 90 & 37,83 & 504 & 13,322 \\
\hline 10 & 100 & 37,83 & 560 & 14,803 \\
\hline
\end{tabular}

Gambar 7 dan Gambar 8 melukiskan olah data-data Tabel 1 dan Tabel 2 dengan regresi linier.

Dari Gambar 7 diperoleh kemiringan grafik sebesar $\mathrm{m}=0,1483 \Omega / \mathrm{cm}=14,83 \Omega / \mathrm{m}$. Pada luas penampang kawat sebesar $A=\pi \mathrm{d}^{2} / 4=1,96 \times 10^{-7} \mathrm{~m}^{2}$, diperoleh nilai resistivitas $\rho_{1}=\mathrm{m} . \mathrm{A}=2,88 \times 10^{-6} \Omega \mathrm{m}$. Dari Gambar 8 diperoleh kemiringan grafik sebesar $\mathrm{m}=0,1468 \Omega / \mathrm{cm}=14,68 \Omega / \mathrm{m}$. Pada luas penampang kawat sebesar $\mathrm{A}=\pi \mathrm{d}^{2} / 4=1,96 \times 10^{-7} \mathrm{~m}^{2}$, diperoleh nilai resistivitas $\rho_{2}=\mathrm{m} . \mathrm{A}=2,87 \times 10^{-6} \Omega \mathrm{m}$.

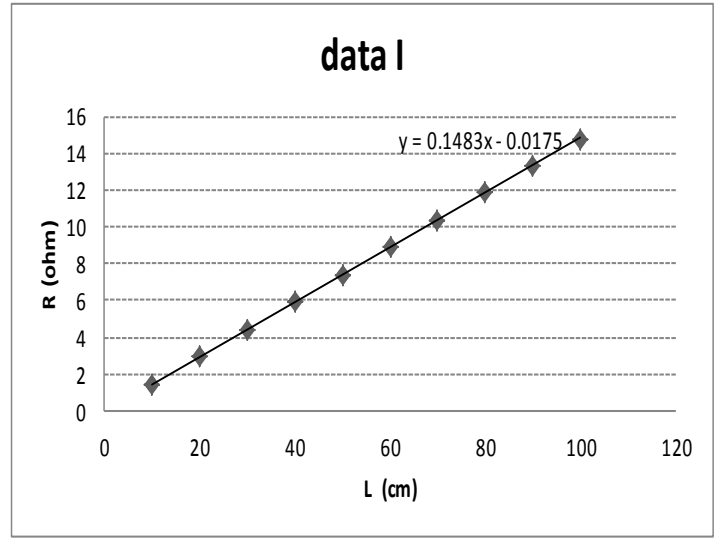

Gambar 7. Grafik data I metode hukum Ohm 


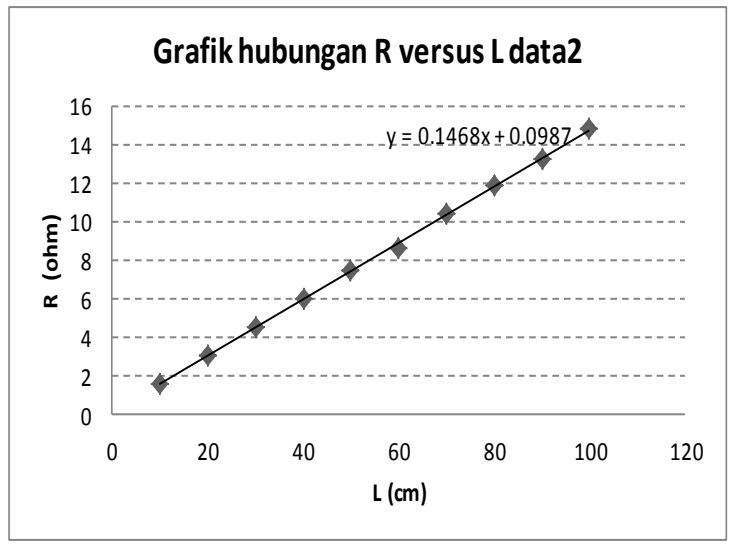

Gambar 8. Grafik hubungan R versus L data II

Nilai rerata diperoleh sebesar $\rho=\left(\rho_{1}+\rho_{1}\right) / 2=2,875 \times 10^{-6} \quad \Omega \mathrm{m}$. Nilai simpangan $\Delta \rho=\left|\rho_{1}-\rho_{2}\right| / 2=|2,88-2,87| \times 10^{-6} / 2=0,01 \times 10^{-6} / 2 \quad \Omega \mathrm{m}$ $=0,005 \times 10^{-6} \Omega \mathrm{m}$. Dari metode hukum Ohm diperoleh nilai resistivitas kawat Nikrom sebesar $\rho \pm \Delta \rho=(2,875 \pm 0,005) \times 10^{-6} \Omega \mathrm{m}$. Hasil ini sedikit berbeda dibandingkan nilai referensi yaitu $\rho=1,00 \times 10^{-6} \Omega \mathrm{m}$, namun berdasarkan Tabel 4 tetap dapat disimpulkan bahwa kawat yang diteliti adalah kawat Nikrom.

Tabel 3. Data eksperimen resistivitas kawat dengan metode Jembatan Wheatstone

\begin{tabular}{|r|r|r|r|r|}
\hline NO & $\mathrm{R}(\mathrm{ohm})$ & $\mathrm{L} 1(\mathrm{~cm})$ & $\mathrm{L} 2(\mathrm{~cm})$ & $\mathrm{L} 1 / \mathrm{L} 2$ \\
\hline 1 & 10 & 0,3 & 99,7 & 0,003 \\
\hline 2 & 20 & 0,5 & 99,5 & 0,005 \\
\hline 3 & 30 & 0,8 & 99,2 & 0,008 \\
\hline 4 & 40 & 1 & 99 & 0,010 \\
\hline 5 & 50 & 1,3 & 98,7 & 0,013 \\
\hline 6 & 60 & 1,7 & 98,3 & 0,017 \\
\hline 7 & 70 & 2,2 & 97,8 & 0,022 \\
\hline 8 & 80 & 2,7 & 97,3 & 0,027 \\
\hline 9 & 90 & 3,2 & 96,8 & 0,033 \\
\hline 10 & 100 & 3,5 & 96,5 & 0,036 \\
\hline
\end{tabular}

Dari Gambar 9 diperoleh kemiringan grafik sebesar $\mathrm{m} \pm \Delta \mathrm{m}=(0,385 \pm 0,02) \times 10^{-2} \quad \Omega^{-1}$. Untuk kawat Nikrom dengan panjang $\mathrm{L}=1 \mathrm{~m}$ dan luas penampang kawat sebesar $A=\pi \mathrm{d}^{2} / 4=1,96 \times 10^{-7} \mathrm{~m}^{2}$,

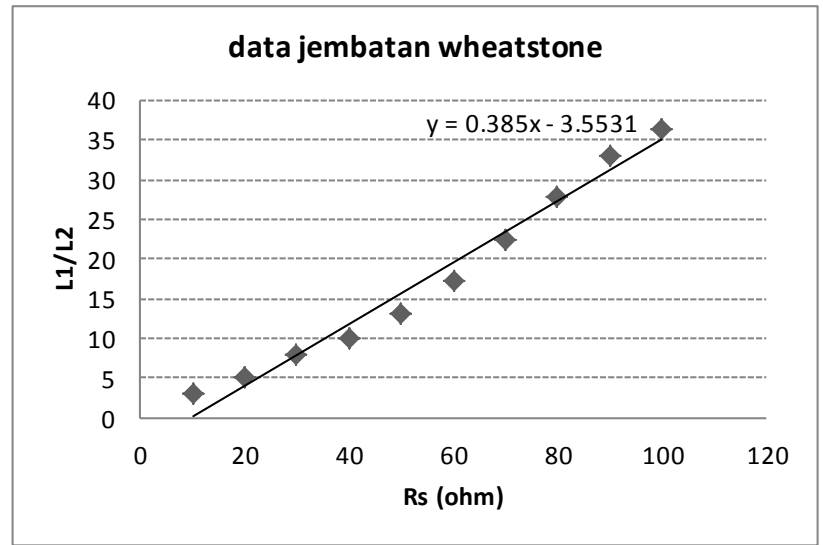

Gambar 9 . Grafik regresi linier data metode jembatan Wheatstone

diperoleh nilai resistivitas $\rho=\mathrm{A} /(\mathrm{m} . \mathrm{L})=5,0 \times 10^{-6}$ $\Omega m$. Ketidakpastian $\Delta \rho$ diperoleh dari perambatan ralat yaitu $\Delta \rho=\rho^{*}(\Delta \mathrm{m} / \mathrm{m})=0,25 \times 10^{-6} \Omega \mathrm{m}$. Dari metode jembatan Wheatstone diperoleh hasil akhir resistivitas kawat adalah $\rho \pm \Delta \rho=(5,0 \pm 0,25) \times 10^{-6} \Omega \mathrm{m}$. Jika dibandingkan dengan nilai referensi, dari dua metode tersebut metode hukum Ohm memberikan hasil yang lebih akurat dibandingkan metode jembatan Wheatstone. Hal ini disebabkan oleh karena pada saat pengambilan data metode jembatan Wheatstone cukup sulit memastikan jarum penunjuk pada Galvanometer berada pada posisi nol.

Sedikit perbedaan hasil penelitian ini dengan nilai referensi disebabkan oleh beberapa hal, diantaranya kawat Nikrom yang diteliti pada penelitian ini merupakan kawat dengan bahan campuran $(\mathrm{Ni}$, $\mathrm{Fe}, \mathrm{Cr}$ ) dimana fraksi /presentasi campuran tidak diketahui apakah sama dengan kawat Nikrom standar.

Perbedaan juga dapat disebabkan oleh ketidakseragaman nilai resistivitas kawat sepanjang kawat, hal ini terlihat adanya karat di bagian tertentu.

Meskipun hasil penelitian ini sedikit berbeda dari nilai referensi, berdasarkan tabel nilai resistivitas beberapa material yang ditunjukkan oleh Tabel 4, nilai resistivitas hasil penelitian ini memberikan kesimpulan akhir bahwa objek kawat yang diteliti adalah kawat Nikrom. 
Tabel 4. Tabel nilai resistivitas beberapa bahan

\begin{tabular}{|l|l|}
\hline Material & Resistivity $\rho(\Omega \cdot \mathrm{m})$ \\
\hline Silver & $1.59 \times 10^{-8}$ \\
\hline Copper & $1.72 \times 10^{-8}$ \\
\hline Gold & $2.44 \times 10^{-8}$ \\
\hline Aluminum & $2.65 \times 10^{-8}$ \\
\hline Tungsten & $5.6 \times 10^{-8}$ \\
\hline Iron & $9.71 \times 10^{-8}$ \\
\hline Platinum & $1.06 \times 10^{-7}$ \\
\hline Steel & $2 \times 10^{-7}$ \\
\hline Lead & $2.2 \times 10^{-7}$ \\
\hline Manganin $(\mathrm{Cu}, \mathrm{Mn}, \mathrm{Ni}$ alloy) & $4.4 \times 10^{-7}$ \\
\hline Constantan $(\mathrm{Cu}, \mathrm{Ni}$ alloy) & $4.9 \times 10^{-7}$ \\
\hline Mercury & $2.6 \times 10^{-7}$ \\
\hline Nichrome (Ni, Fe, Cr alloy) & $1 \times 10^{-6}$ \\
\hline Graphite (pure) & $3.5 \times 10^{5}$ \\
\hline Carbon & $(3.5-60) \times 10^{5}$ \\
\hline Germanium (pure) & 0.6 \\
\hline Germanium & $(1-600) \times 10^{-3}$ \\
\hline
\end{tabular}

(diakses dari www.csivc.csi.cuny.edu)

\section{KESIMPULAN}

Nilai resistivitas suatu kawat penghantar dapat ditentukan secara experimental dengan menggunakan metode hukum Ohm dan metode jembatan Wheatstone. Dari penelitian ini dengan menggunakan metode hukumOhm diperoleh nilai resistivitas kawat Nikrom sebesar $\rho \pm \Delta \rho=(2,875 \pm 0,005) \times 10^{-6} \quad \Omega \mathrm{m}$ dan dengan metode jembatan Wheatstone diperoleh nilai resistivitas kawat Nikrom sebesar $\rho \pm \Delta \rho=(5,00 \pm 0,25) \times 10^{-6} \Omega \mathrm{m}$. Dari penelitian ini diharapkan pemahaman mahasiswa mengenai konsep kelistrikan semakin luas.

\section{DAFTAR PUSTAKA}

Giancolli, 2001, Fisika Jilid 2, Penerbit Erlangga, Jakarta.

Squires, G.L., 1968, Practical Physics, New York: McGraw-Hill.

Sutrisno, 1986, Elektronika, Teori Dasar dan Penerapannya, Jilid 1, Penerbit ITB, Bandung.

Tim Penyusun Praktikum Fisika Dasar, 2010, Panduan Praktikum Fisika Dasar FMIPA UGM, Yogyakarta.

Tim Penyusun Panduan Praktikum Fisika Dasar, 2013, Panduan Praktikum Fisika Dasar Fakultas Saintek UIN Sunan Kalijaga, Yogyakarta.

Tipler A, P., 2001, Fisika Untuk Sains dan Teknik, Edisi ketiga, jilid 2, Erlangga, Jakarta.

www.csivc.csi.cuny.edu diunduh pada 1 Nopember 2016. 